\title{
Adubação verde com espécies espontâneas da caatinga no cultivo do rabanete em
} sucessão a rúcula

\section{Green manuring with spontaneous species of the savanna in radish cultivation in succession to rocket}

\author{
Whenia Benevides Ramalho ${ }^{1}$, Paulo César Ferreira Linhares ${ }^{2}$, Janilson Pinheiro de Assis ${ }^{3}$, Alany Moisa Bezerra de \\ Almeida ${ }^{4}$, Lauvia Moesia Morais Cunha ${ }^{5}$
}

\begin{abstract}
Resumo: O rabanete é uma planta de ciclo curto e o ambiente exerce grande interferência na qualidade de suas raízes $\mathrm{O}$ efeito residual da adubação anterior em cultivos subsequente é de suma importância, uma vez que a fertilização do solo em uma atividade tão intensa, como a olericultura, aumentaria o custo de produção sempre que fosse implantada uma nova cultura. Este trabalho foi conduzido na fazenda experimental Rafael Fernandes, pertencente à Universidade Federal Rural do Semi-Árido, Mossoró-RN, no período de julho a novembro de 2010. Objetivou-se avaliar a adubação verde com espécies espontâneas da caatinga no cultivo do rabanete em sucessão ao cultivo da rúcula. $O$ rabanete assim como a rúcula foi plantado em parcelas de $1,2 \times 1,2 \mathrm{~m}$ sendo avaliado o efeito residual das espécies espontâneas da caatinga (Jitirana, flor-de-seda e mata-pasto) nas quantidades $(0 ; 6,0 ; 12,0 ; 18,0 ; 24,0$ e 30,0 t ha-1). Após a retirada do primeiro cultivo, semearam-se sementes de rabanete nas parcelas referente aos tratamentos acima citados. O delineamento experimental foi em blocos casualizados com três repetições, no esquema fatorial $6 \times 3$, sendo seis quantidades de adubos verdes e três tipos de adubos verdes (jitirana; mata-pasto e flor-deseda). A cultivar de rabanete plantado foi a Crimson Gigante. As características avaliadas do rabanete foram: altura de planta, diâmetro de raiz; número de folhas; produtividade comercial e raízes mais parte aérea. $\mathrm{O}$ efeito residual da quantidade $23 \mathrm{t}$ ha1 de adubo verde promoveu maior incremento na produtividade comercial e de raízes mais parte aérea, cujos valores máximos foram de 1,5 e 2,26 kg m-2 de canteiro, respectivamente.
\end{abstract}

Palavras-chave: Efeito residual. Jitirana. Flor-de-seda. Mata-pasto.

\begin{abstract}
The radish is a short-cycle plant and the environment has great interference as its roots the residual effect of previous fertilization in subsequent crops is extremely important, since soil fertilization in such an intense activity, such as horticulture, increase the cost of production when a new culture was implanted. This study was conducted at the experimental farm Rafael Fernandes, belonging to the Universidade Federal Rural do Semi-Arido, Mossoró-RN, in the period from July to November 2010. The objective was to evaluate green manures with spontaneous species of the savanna in radish cultivation succession to the cultivation of arugula. Radish as well as the rocket was planted in plots of $1.2 \times 1.2 \mathrm{~m}$ being evaluated the residual effect of spontaneous species of caatinga (scarlet starglory, fleur-de-silk and kill pasture) in the quantities $(0,6.0$; $12.0 ; 18.0 ; 24.0$ and $30.0 \mathrm{t}$ ha-1). After removal of the first crop, seeded radish seeds in the portions regarding the above mentioned treatments. The experimental design was a randomized block design with three replications, in a factorial $3 \times 6$, six amounts of green manures and three types of green manures (scarlet starglory, kill grass and flower-de-silk). The cultivar planted radish was the Crimson Giant. The evaluated Radish characteristics were: plant height, root diameter; number of sheets; business productivity and more aerial roots. The residual effect of the amount $23 \mathrm{t}$ ha-1 of green manure promoted greater increase in business productivity and more aerial roots that maximum values were 1.5 and $2.26 \mathrm{~kg} \mathrm{~m}-2$ site, respectively.
\end{abstract}

Key words: Residual effect. Scarlet starglory. Silk-flower. Forest-pasture.

\footnotetext{
*Autor para correspondência

Recebido para publicação em 10/02/2016; aprovado em 10/06/2016

${ }^{1}$ Engenheira agrônoma, Mestre em Sistemas Agroindustriais - UFCG/CCTA, Campus Pombal PB -. E-mail:whenia_benevides@ @otmail.com

${ }^{2}$ Engenheiro Agrônomo, Doutor em Agronomia- Pesquisador da Universidade Federal Rural do Semiárido (UFERSA) E-mail: paulolinhares@ ufersa.edu.br; paulojitirana@yahoo.com.br.

${ }^{3}$ Eng. Agrônomo, Doutor em agronomia - Professor da universidade Federal Rural do Semiárido (UFERSA), E-mail: janilson@ ufersa.edu.br

${ }^{4}$ Engenheira agrônoma, Mestranda em Sistemas Agroindustriais, Universidade Federal de Campina Grande, E-mail: alanymoisa1@ hotmail.com

${ }^{5}$ Engenheira agrônoma, Mestranda em Sistemas Agroindustriais, Universidade Federal de Campina Grande, E-mail: lauvia.agro@hotmail.com
} 


\section{INTRODUÇÃO}

O rabanete (Raphanus sativus L.) é uma Brassicaceae de porte reduzido e que, nas cultivares de maior aceitação, produz raízes globulares, de coloração escarlate-brilhante e polpa branca. Adapta-se melhor ao cultivo no outono inverno, tolerando bem o frio e geadas leves. A colheita é feita de 3 a 6 semanas após a semeadura, quando atingem o ponto de colheita (FILGUEIRA, 2008). Tem como vantagem do seu cultivo a possibilidade de obter ganhos durante o tempo transcorrido em comparação a outras culturas de ciclo mais longo.

As hortaliças de modo geral reagem bem à adubação orgânica, tanto em produtividade quanto em qualidade dos produtos obtidos. Nesse sentido, uma alternativa viável para os agricultores que trabalham em regime familiar e que busca aproveitar os recursos da propriedade seria a utilização da adubação verde. No entanto, os mesmos devem estar atentos ao tempo de incorporação dos resíduos em relação ao ciclo da cultura, tendo em vista que, se não houver uma sincronia entre a disponibilidade de nutrientes e o momento de maior exigência da cultura, a prática torna-se inviável (LINHARES, 2013). Deve-se ter também uma maior atenção na escolha da espécie de adubo verde a ser introduzida, uma vez que elas apresentam características próprias que devem ser consideradas para o melhor aproveitamento desta prática.

Entre as espécies utilizadas como adubo verde, se destaca as leguminosas por promover maior beneficio ao solo em virtude da fixação biológica de nitrogênio através da simbiose das bactérias existentes em seus sistemas radiculares. No entanto, afirma Favero et al. (2000), que as espécies espontâneas podem promover os mesmos benefícios que as espécies introduzidas no que tange a produção de fitomassa e ciclagem de nutrientes.

Espécies espontâneas da caatinga de fácil ocorrência na região de estudo no período chuvoso, jitirana (Merremia aegyptia L.) e mata-pasto (Senna uniflora) e durante todo ano, a flor-de-seda (Calotropis procera), tem sido utilizado como adubo verde na produção orgânica de hortaliças, contribuindo para o aumento em produtividade (LINHARES et al., 2009a e b; LINHARES et al., 2012). Nesse sentido, um importante aspecto a ser considerado quando se estuda a produção orgânica de hortaliças, especialmente utilizando adubos verdes, é o efeito residual da adubação anterior na produtividade subsequente, uma vez que a fertilização do solo é uma atividade tão intensa, como a olericultura, aumentaria o custo de produção sempre que fosse implantada uma nova cultura. Isto porque a adubação orgânica proporciona maior disponibilidade de nutrientes ao longo do tempo o que favorece um melhor aproveitamento do mesmo.

Assim, o presente estudo, teve como objetivo avaliar a adubação verde com espécies espontâneas da caatinga no cultivo do rabanete em sucessão a rúcula.

\section{MATERIAL E MÉTODOS}

O experimento foi conduzido na Fazenda Experimental Rafael Fernandes pertencente à Universidade Federal Rural do Semi-Árido (UFERSA), Mossoró-RN, no período de julho a novembro de 2010. Em solo classificado como Latossolo Vermelho Amarelo Argissólico franco arenoso (EMBRAPA, 2006). Antes da instalação do primeiro experimento foram retiradas amostras de solo na profundidade de $0-20 \mathrm{~cm}$, em seguida foram analisados no Laboratório de Química e Fertilidade de Solos da UFERSA, cujos resultados foram os seguintes: pH (água 1:2,5) =6,0; $\mathrm{Ca}=2,0$ cmolc dm $\mathrm{dm}^{-3} ; \mathrm{Mg}=$ $0,50 \mathrm{cmolc} \mathrm{dm}^{-3} ; \mathrm{K}=0,12$ cmolc dm $\mathrm{dm}^{-3} ; \mathrm{Na}=0,20 \mathrm{cmolc} \mathrm{dm}^{-3}$; $\mathrm{P}=27,7 \mathrm{mg} \mathrm{dm}^{-3}$ e M.O. $=0,36 \%$.

$\mathrm{O}$ delineamento experimental utilizado foi o de blocos completos ao acaso com os tratamentos arranjados em esquema fatorial $6 \times 3$, com três repetições. Os tratamentos consistiram do efeito residual da combinação de seis quantidades de adubos verdes $(0 ; 6,0 ; 12,0 ; 18,0 ; 24,0$ e $30,0 \mathrm{t}$ $\mathrm{ha}^{-1}$ em base seca) com três tipos de adubos (jitirana, flor-deseda e mata-pasto). A cultura do rabanete foi instalada por ocasião da retirada do cultivo de rúcula.

As espécies espontâneas foram coletadas da vegetação nativa nas proximidades do campus da UFERSA, no início do período da floração, quando a planta apresenta o máximo de concentração de nutrientes. Depois triturados em máquina forrageira, secos ao sol, em seguida armazenados em sacos de ráfia com teor de umidade de $10 \% ; 8 \%$ e $11 \%$ para jitirana, flor-de-seda e mata-pasto respectivamente. Por ocasião da instalação do experimento, foram retiradas cinco amostras para análise, cuja concentração química de $\mathrm{N}$; P e K para jitirana foram de 24,$6 ; 10,5$ e $10,3 \mathrm{~g} \mathrm{~kg}^{-1}$ respectivamente, para flor-de-seda de 22,7; 10,0 e 25,0 $\mathrm{g} \mathrm{kg}^{-1}$ respectivamente, para o mata-pasto foi de 23,$6 ; 10,2$ e $10,0 \mathrm{~g} \mathrm{~kg}^{-1}$ respectivamente. Quantificados e incorporados na camada de $0-20 \mathrm{~cm}$ do solo nas parcelas experimentais referente a cada tratamento.

Cada parcela constou de seis fileiras de plantas espaçadas de $0,2 \mathrm{~m}$ x $0,1 \mathrm{~m}$ com doze plantas por fileiras, sendo as fileiras laterais consideradas bordaduras. A área total das parcelas foi de $1,44 \mathrm{~m}^{2}$ e a área útil de $0,80 \mathrm{~m}^{2}$, contendo 40 plantas. A cultivar utilizada de rabanete foi a Crimson Gigante.

A propagação do rabanete foi por sementes, no sistema de semeadura direta, sendo efetuado o semeio em 16/10/2010, efetuando-se o desbaste aos 10 dias após a emergência das plantas (DAE).

A colheita do rabanete foi realizada aos 30 dias após a semeadura em 16/11/2010. As características avaliadas foram: altura de planta (determinada em uma amostra de vinte plantas, medidas aleatoriamente da área útil, através de uma régua, a partir do nível do solo até a inflexão da folha mais alta e expressa em centímetro), diâmetro de raízes (determinado na mesma amostra de vinte plantas, e expressa em centímetro), número de folhas (determinado na mesma amostra de vinte plantas, e expressa em média planta ${ }^{-1}$ ), produtividade comercial de raízes (determinada a partir da massa fresca de raízes das plantas da área útil livres de rachaduras, não isoporizadas com diâmetro $\geq 20 \mathrm{~mm}$ (CARDOSO; HIRAKI, 2001) e expressa em $\mathrm{kg} \mathrm{m}^{-2} \mathrm{de}$ canteiro), produtividade de raízes mais parte aérea (determinada a partir da massa fresca de raízes das plantas mais parte aérea, presentes na área útil, expressa $\mathrm{em} \mathrm{kg} \mathrm{m}^{-2} \mathrm{de}$ canteiro).

Análises de variância para as características avaliadas foram realizadas através do aplicativo ESTAT (KRONKA; BANZATO, 1995). Para o fator quantidade de adubo (espécies espontâneas), o procedimento de ajustamento de curva de resposta foi realizado através do software Table Curve (JANDEL SCIENTIFIC, 1991), e para o fator qualitativo, utilizou-se o teste de Tukey ao nível de 5\% de probabilidade para se fazerem as comparações entre os tipos de adubos verdes. 


\section{RESULTADOS E DISCUSSÃO}

Neste experimento não se observou interação significativa entre as quantidades de espécies espontâneas da caatinga e os tipos de espécies incorporadas ao solo para todas as características avaliadas. Isso demonstra que os fatores tiveram comportamento independente entre si. No entanto, todas as características apresentaram significância ao nível de 5\% de probabilidade. As espécies espontâneas do bioma caatinga (jitirana, mata-pasto e flor-de-seda), provavelmente contribui para a melhoria das condições físicas e químicas do solo o que favoreceu o melhor desempenho do rabanete em cultivo sucessivo da rúcula.

Em relação às quantidades de espécies espontâneas, observou-se efeito linear crescente para a altura de planta, tendo obtido valor médio de $9,9 \mathrm{~cm}^{-1 a n t a}{ }^{-1}$ na quantidade de $30,0 \mathrm{t} \mathrm{ha}^{-1}$, correspondendo há um acréscimo médio de $8,1 \mathrm{~cm}$ planta ${ }^{-1}$ entre a menor quantidade $\left(0 \mathrm{t} \mathrm{ha}^{-1}\right)$ e a maior (Figura 1). Em relação às espécies espontâneas, a jitirana foi estatisticamente superior à flor-de-seda e mata-pasto, com valores médios de 11,$0 ; 10,0$ e 9,2 cm planta ${ }^{-1}$, respectivamente (Tabela 1). Resultados superiores foram encontrados por Linhares et al. (2011) avaliando quantidades e tempos de decomposição da flor-de-seda no desempenho do rabanete observando uma altura média das plantas de rabanete de $12,95 \mathrm{~cm}$ planta $^{-1}$, assim como Batista (2011), estudando a adubação verde na produtividade, qualidade e rentabilidade de rabanete, encontrou a máxima altura de plantas de $13,9 \mathrm{~cm}$ na quantidade de 21,0 $\mathrm{t} \mathrm{ha}^{-1}$ de mata pasto. Essa superioridade encontrado por Linhares et al. (2011) e Batista (2011) se deve provavelmente ao fato dos autores estarem produzindo rabanete em primeiro cultivo, consequentemente contribuiu para que houvesse uma maior disponibilidade de nutrientes ao solo, principalmente o nitrogênio responsável pela expansão foliar.

Figura 1 - Altura de planta de rabanete sob diferentes quantidades de espécies espontâneas do bioma caatinga incorporadas ao solo. UFERSA, Mossoró-RN, 2010.

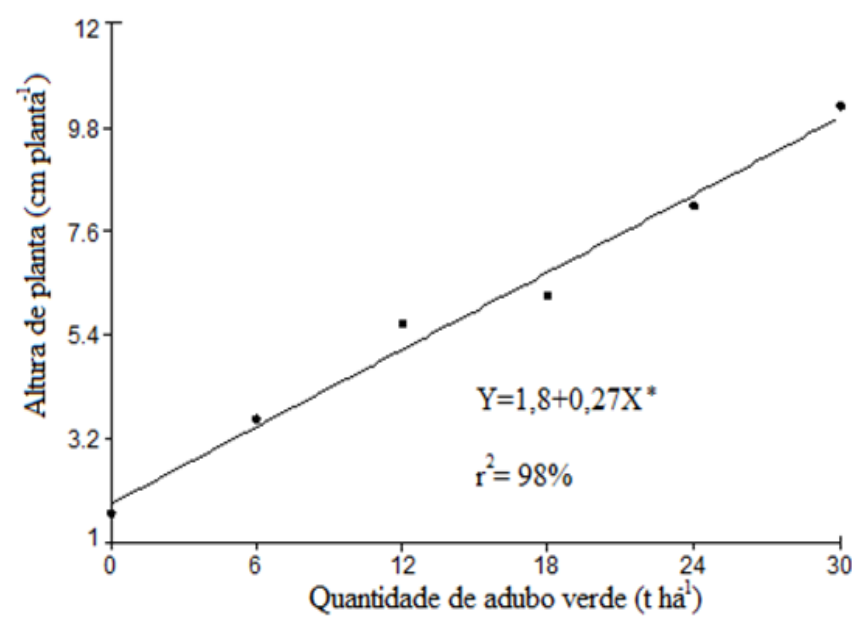

Foi ajustada uma equação quadrática para a característica diâmetro de planta de rabanete em função do efeito residual das diferentes quantidades de espécies espontâneas do bioma caatinga incorporada ao solo, com diâmetro médio máximo de raízes de rabanete de $3,8 \mathrm{~cm}$ planta $^{-1}$ na quantidade de 23,9 $\mathrm{t} \mathrm{ha}^{-1}$, Apresentando diferença de 2,37 cm para a menor quantidade de espécie espontânea (0 t ha ${ }^{-1}$ ), que teve diâmetro médio de $1,53 \mathrm{~cm}$ planta $^{-1}$ (Figura 2). Já, para as espécies espontâneas, jitirana e flor-de-seda foram estatisticamente superior a espécie mata-pasto, com valores médio de 4,6; 4,4 e 3,3 $\mathrm{cm}$ planta $^{-1}$, respectivamente (Tabela 1). Os resultados encontrados foram superiores aos de Silva et al. (2006) que obtiveram média de $1,82 \mathrm{~cm}_{\text {planta }}{ }^{-1}$ adubada com esterco bovino, avaliando o crescimento e produção do rabanete cultivado com diferentes doses de húmus de minhoca e esterco bovino. Rodrigues; Reis; Reis (2013) encontraram diâmetro médio de 3,23 $\mathrm{cm}$ planta $^{-1}$, com a utilização de esterco bovino analisando a utilização de estercos (bovino e de galinha) em substituição a adubação mineral na cultura do rabanete. Assim como, Vitti et al. (2007) estudando o rabanete em ambiente fechado com adubação orgânica, encontraram uma média de 3,67 cm.planta ${ }^{-1}$ na presença de $20 \mathrm{~g}$ de esterco bovino/vaso.

Figura 2 - Diâmetro de rabanete sob diferentes quantidades de espécies espontâneas do bioma caatinga incorporadas ao solo. UFERSA, Mossoró-RN, 2010.

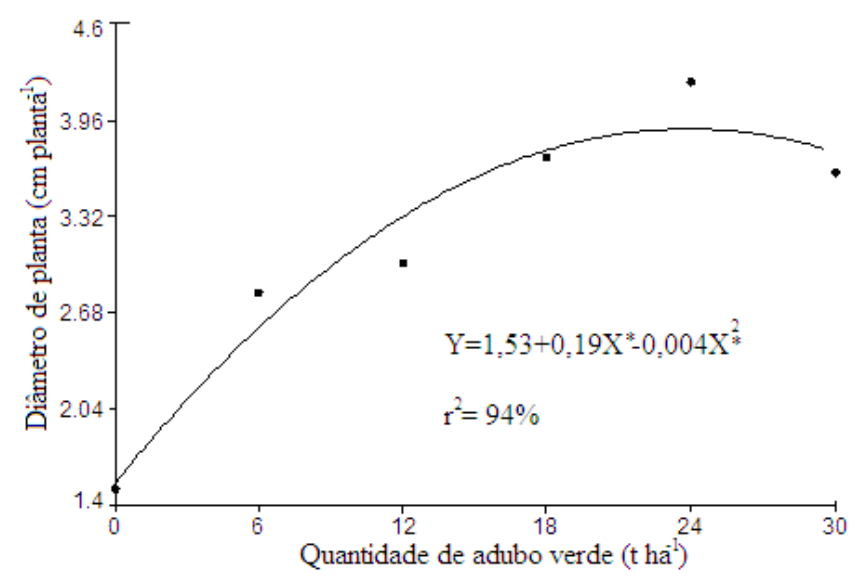

Verificou-se acréscimo no efeito residual das diferentes quantidades de espécies espontâneas, com valor médio de 7 folhas planta ${ }^{-1}$ na quantidade de 30,0 t ha ${ }^{-1}$ (Figura 3). Em relação às espécies espontâneas, não se observou efeito significativo, com valores médios de 7,0; 7,0 e 6,4 para jitirana, flor-de-seda e mata-pasto respectivamente (Tabela 1). O número de folhas por planta é de suma importância, haja vista ser esse órgão no vegetal responsável pela fotossíntese, sendo comercializado com a raiz do rabanete. Valores superiores foram encontrados por Linhares et al. (2010) avaliando o efeito residual da jitirana na quantidade de $15,6 \mathrm{t}$ $\mathrm{ha}^{-1}$ de jitirana incorporada, encontraram valor médio de 8 folhas planta ${ }^{-1}$ de rabanete. 
Figura 3 - Número de folhas planta $^{-1}$ de rabanete sob diferentes quantidades de espécies espontâneas do bioma caatinga incorporadas ao solo. UFERSA, Mossoró-RN, 2010.

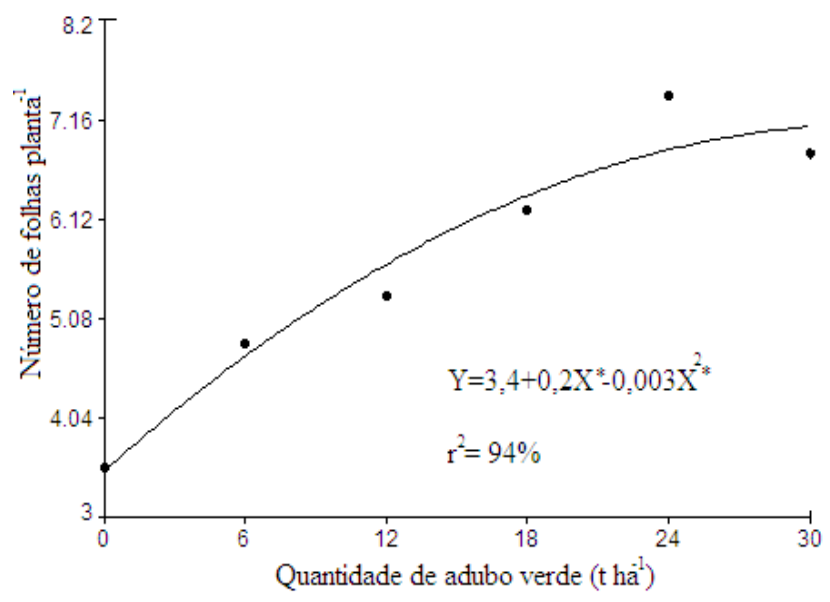

Houve aumento na produtividade comercial de raízes de rabanete sob o efeito residual das diferentes quantidades de espécies espontâneas do bioma caatinga, com produtividade média máxima de $1,50 \mathrm{~kg} \mathrm{~m}^{-2}$ de canteiro na quantidade de $27,6 \mathrm{t} \mathrm{ha}^{-1}$, correspondendo a um acréscimo médio de $1,27 \mathrm{~kg}$ $\mathrm{m}^{-2}$ de canteiro em relação ao tratamento ausência de adubação $\left(0 \mathrm{t} \mathrm{ha}^{-1}\right)$ (Figura 4). Entre as espécies espontâneas, a jitirana foi superior a flor-de-seda e o mata-pasto, porém não houve diferença estatística entre a flor-de-seda e matapasto, com valores médios de 1,$5 ; 1,1$ e $1,0 \mathrm{~kg} \mathrm{~m}^{-2}$ de canteiro (Tabela 1). A vantagem de adicionar resíduos vegetais no solo consiste não só na fertilização imediata, mas na capacidade de melhoria da estrutura do solo e na disponibilidade de nutrientes em períodos subsequente ao primeiro cultivo, garantindo ao produtor orgânico a possibilidade de produzir mais de um cultivo sem a necessidade de fertilizar o solo. Esses resultados foram superiores ao encontrado por Linhares et al. (2010) avaliando o efeito residual da jitirana na produtividade comercial do rabanete, obtiveram produtividade média de $9529 \mathrm{~kg} \mathrm{ha}^{-1}$, equivalente a $0,959 \mathrm{~kg}$ $\mathrm{m}^{-2}$ de canteiro. Assim como Batista (2011), estudando a adubação verde na produtividade, qualidade e rentabilidade de rabanete, encontrou produtividade média de $12,1 \mathrm{t} \mathrm{ha}^{-1}$, equivalente a $1,210 \mathrm{~kg} \mathrm{~m}^{2}$ de canteiro com a adição de $21,0 \mathrm{t}$ $\mathrm{ha}^{-1}$ de jitirana incorporada ao solo. Já, Linhares et al. (2013) obtiveram produtividade máxima de $1,380 \mathrm{~kg} \mathrm{~m}^{2}$ de canteiro de rabanete utilizando quantidade de $14,5 \mathrm{t} \mathrm{ha}^{-1}$ de jitirana incorporada ao solo, o que se assemelha a referida pesquisa.
Figura 4 - Produtividade comercial de raízes de rabanete sob diferentes quantidades de espécies espontâneas do bioma caatinga incorporadas ao solo. UFERSA, Mossoró-RN, 2010.

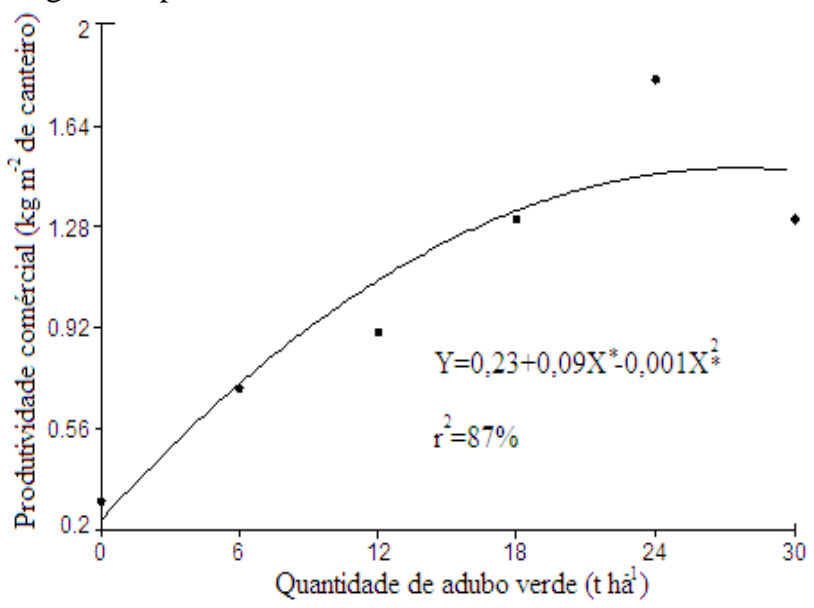

$\mathrm{Na}$ produtividade de raízes mais parte aérea, houve aumento na produtividade em função do efeito residual das diferentes quantidades de espécies espontâneas, com valor médio máximo de $2,30 \mathrm{~kg} \mathrm{~m}^{-2}$ de canteiro na quantidade de 25,2 t ha $^{-1}$ (Figuras 5). Para as espécies espontâneas, a jitirana foi estatisticamente superior às demais espécies com valor médio de $2,3 \mathrm{~kg} \mathrm{~m}^{-2}$ de canteiro (Tabela 1). Essa avaliação é suma importância, haja vista ser essa forma de comercialização pelos produtores locais nas gôndolas de supermercado e nas feiras de hortaliças em Mossoró-RN.

Figura 5 - Raízes mais parte aérea do rabanete sob diferentes quantidades de espécies espontâneas do bioma caatinga incorporadas ao solo. UFERSA, Mossoró-RN, 2010.

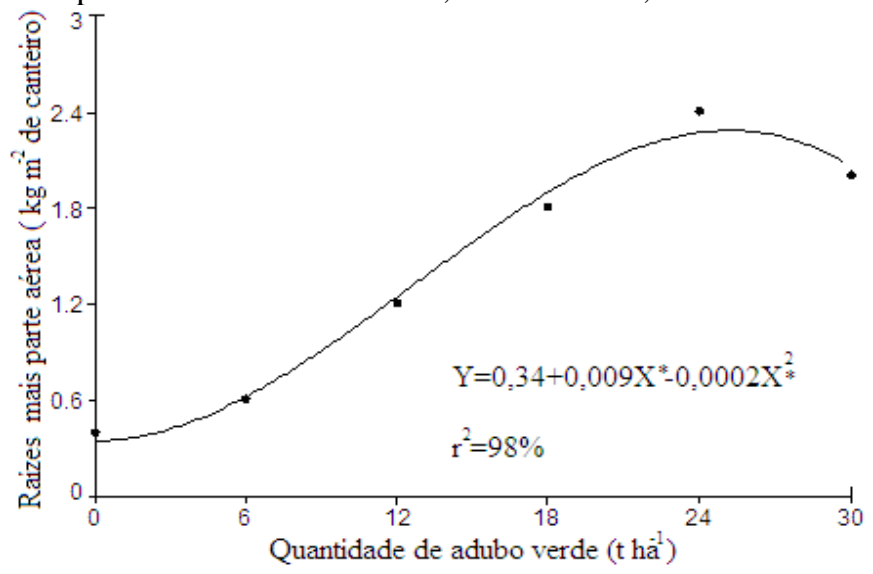

Tabela 1- Altura de planta (AT), Diâmetro de rabanete (DIÂ), Número de folhas (NF), Produtividade comercial (PC), Raiz mais parte aérea (RPA) de rabanete sob diferentes espécies do bioma caatinga incorporada ao solo. UFERSA, Mossoró-RN, 2010.

\begin{tabular}{|c|c|c|c|c|c|}
\hline Espécies espontâneas & AP & DIÂA & $\mathrm{NF}$ & $\mathrm{PC}$ & RPA \\
\hline & $\mathrm{Y}$ & $\mathrm{Y}$ & $\mathrm{Y}$ & $\mathrm{Y}$ & $\mathrm{Y}$ \\
\hline Jitirana & $11,0 \mathrm{a}$ & $4,6 \mathrm{a}$ & $7,0 \mathrm{a}$ & $1,5 \mathrm{a}$ & $2,3 \mathrm{a}$ \\
\hline Flor-de-seda & $10,0 \mathrm{~b}$ & $4,4 \mathrm{a}$ & $7,0 \mathrm{a}$ & $1,1 \mathrm{~b}$ & $1,8 \mathrm{~b}$ \\
\hline Mata-pasto & $9,2 \mathrm{c}$ & $3,3 b$ & $6,4 \mathrm{a}$ & $1,0 \mathrm{~b}$ & $1,6 \mathrm{~b}$ \\
\hline Média & 10,0 & 4,1 & 4,1 & 1,2 & 1,2 \\
\hline
\end{tabular}

${ }^{\mathrm{Y}}$ Médias seguidas de letras diferentes na coluna diferem entre si ao nível de 5\% probabilidade pelo teste de Tukey. 


\section{CONCLUSÕES}

O efeito residual da quantidade $23 \mathrm{t} \mathrm{ha}^{-1}$ de adubo verde promoveu maior incremento na produtividade comercial e de raízes mais parte aérea, cujos valores máximos foram de 1,5 e $2,26 \mathrm{~kg} \mathrm{~m}^{-2}$ de canteiro, respectivamente.

\section{REFERÊNCIAS BIBLIOGRÁFICAS}

BATISTA, M. A. V. Adubação verde na produtividade, qualidade e rentabilidade de beterraba e rabanete. Mossoró; Tese (Doutorado em Agronomia: Fitotecnia) - UFERSA, 2011, 123p.

\section{EMPRESA BRASILEIRA DE PESQUISA} AGROPECUÁRIA - EMBRAPA. Sistema brasileiro de classificação de solos. 2.ed. Rio de Janeiro: EMBRAPA, 2006, 306p.

FAVERO, C.; JUCKSCH, I.; COSTA, L. M.; ALVARENGA, R. C.; NEVES, J. C. L. Crescimento e acúmulo de nutrientes por plantas espontâneas e por leguminosas utilizadas para adubação verde. Revista Brasileira de Ciência de Solo, Viçosa, v. 24, n. 2, p. 171-177, 2000.

FILGUEIRA, F.A.R. Novo manual de olericultura: Agrotecnologia moderna na produção e comercialização de hortaliças. 3 ed. Viçosa: UFV, 2008, 421p.

JANDEL SCIENTIFIC. Table curve: curve fitting software. Corte Madera, CA: Jandel Scientific, 1991, p. 280.

KRONKA, S. N.; BANZATO, D. A. ESTAT: sistema para análise estatística versão 2. 3.ed. Jaboticabal: Funep, 1995, p.243.

LINHARES, P. C. F. Adubação verde como condicionadora do solo. Revista Campo e negócios, Minas Gerais, v.11, n.127, p.22-23, 2013.

LINHARES, P. C. F.; PEREIRA, M. F. S.; DA SILVA, M. L.; MARACAJÁ, P. B.; SOUZA, A. A. T. Otimização da quantidade de jitirana incorporada ao solo no rendimento agronômico do rabanete. Agropecuária Científica no Semiárido, Patos, v.9, n.2, p.42-48, 2013.

LINHARES PCF; PEREIRA MFS; ASSIS JP; BEZERRA AKH. 2012. Quantidades e tempos de decomposição da jitirana no desempenho agronômico do coentro. Ciência Rural, Santa Maria, v. 42, 243-248, 2012.

LINHARES, P. C. F.; SILVA, M. L.; PEREIRA, M. F. S.; BEZERRA, A. K. H.; Paiva, A.C. C.; quantidades e tempos de decomposição da flor-de-seda no desempenho agronômico do rabanete. Revista Verde, Pombal, v.6, n.1, p.168 - 173, 2011.

LINHARES, P. C. F.; PEREIRA, M. F. S.; OLIVEIRA, B. S.; HENRIQUES, G. P. S. A. MARACAJÁ, P. B.; Produtividade de rabanete em sistema orgânico de produção. Revista Verde, Pombal, v. 5, n. 5, p. 94-101, 2010.

LINHARES, P. C. F.; SILVA, M. L.; PEREIRA, M. F. S.; BRITO, B. F.; DINIZ FILHO, E. T. Velocidade de decomposição do mata-pasto no desempenho agronômico da rúcula (Eruca sativa) cv. Cultivada. Revista Verde, Pombal, v.4, n.2, p. $106-112,2009 a$.

LINHARES, P. C. F.; SILVA, M. L.; BORGONHA, W.; MARACAJÁ, P. B.; MADALENA, J. A. S. Velocidade de decomposição da flor-de-seda no desempenho agronomico da rúcula cv. Cultivada. Revista Verde, Pombal, v.4, n.2, p. 46 50, 2009b.

RODRIGUES, J. F.; REIS, J. M. R.; REIS, M. A. Utilização de estercos em substituição a adubação mineral na cultura do rabanete. Revista Trópica: Ciências Agrárias e Biológicas, Chapadinha, v.7, n. 2, p.160-168, 2013.

SILVA, C. J.; COSTA, C. C.; DUDA, C.; TIMOSSI, P. C.; LEITE, I. C. Crescimento e produção de rabanete cultivado com diferentes doses de húmus de minhoca e esterco bovino. Revista Ceres, Viçosa, v. 53, n. 305, p. 25-30, 2006.

VITTI, M. R.; VIDAL, M. B.; MORSELLI, T. B. G. A.; FARIA, J. L. C.; Resposta do Rabanete a Adubação Orgânica em Ambiente Protegido. Revista Brasileira de Agroecologia, Cruz Alta, v. 2, n. 1, p. 1158-1161, 2007. 